\title{
Die Redaktion der SÄZ ab 1. Januar 2008
}

Per 1. Januar 2008 wurde die Redaktion der Schweizerischen Ärztezeitung um mehrere Mitglieder erweitert. Wir haben dies zum Anlass genommen, unserer Leserschaft alle Redaktorinnen und Redaktoren inklusive Fachredaktionen im Bild vorzustellen. Zur Redaktionserweiterung siehe auch die Kolumne «Zu guter Letzt» auf der letzten Seite dieser Ausgabe.

\section{Redaktion}

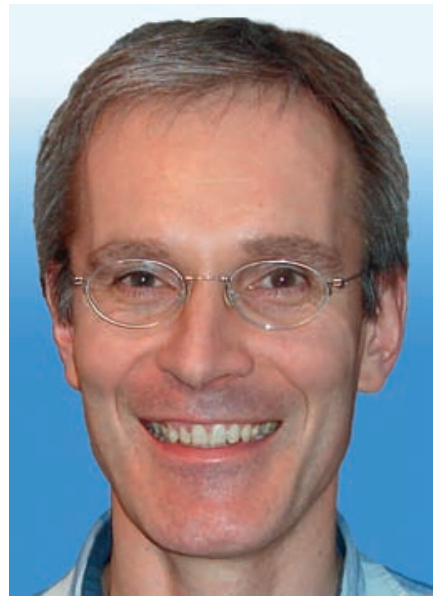

Dr. med. et lic. phil. Bruno Kesseli (Chefredaktor)

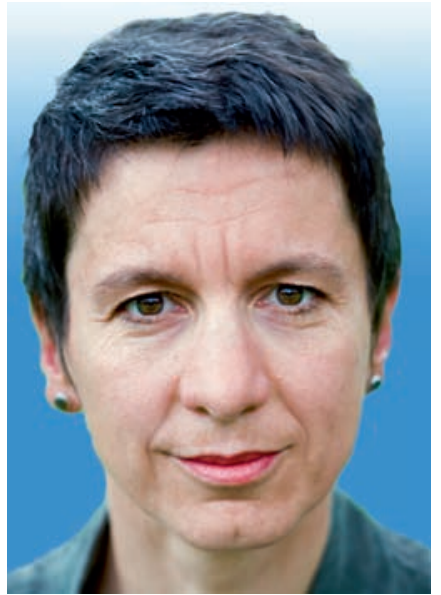

lic. oec. Anna Sax, MHA

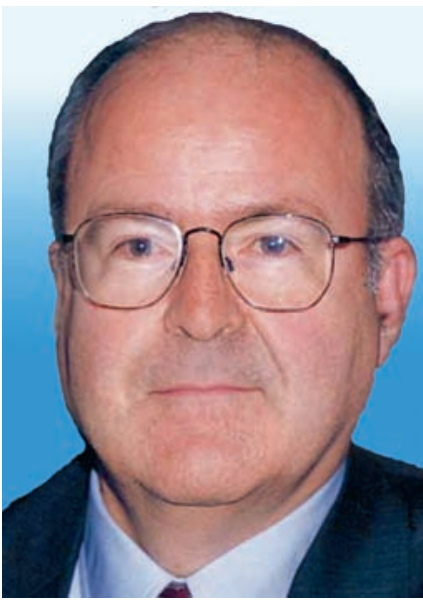

Dr. med. Werner Bauer

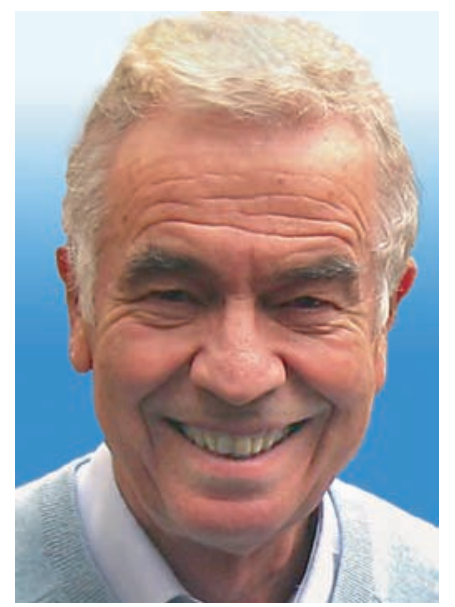

Prof. Dr. med. Hans Stalder

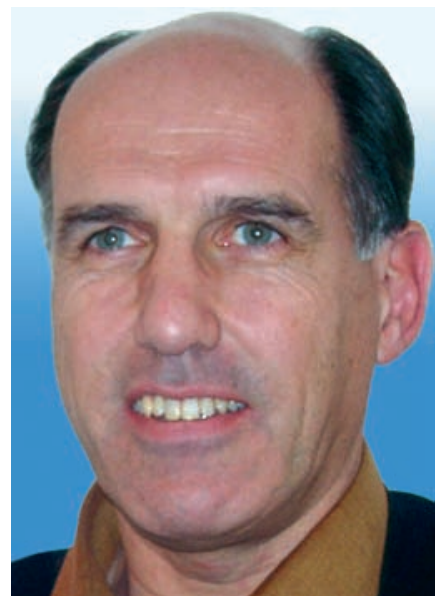

Dr. med.

Jacques de Haller (FMH)

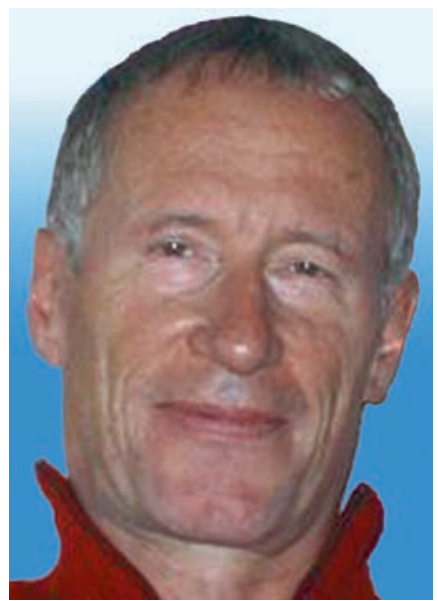

Dr. med. Erhard Taverna

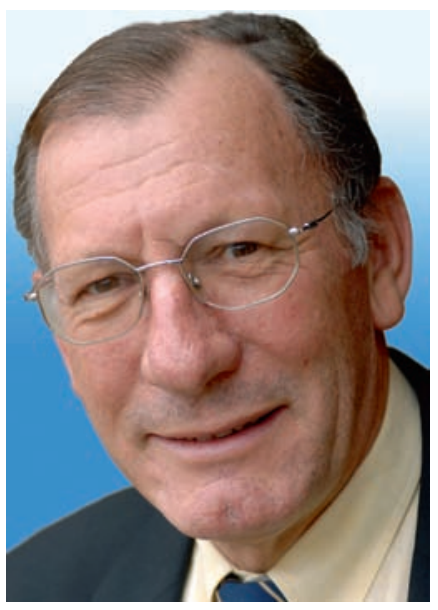

PD Dr. med. Jean Martin

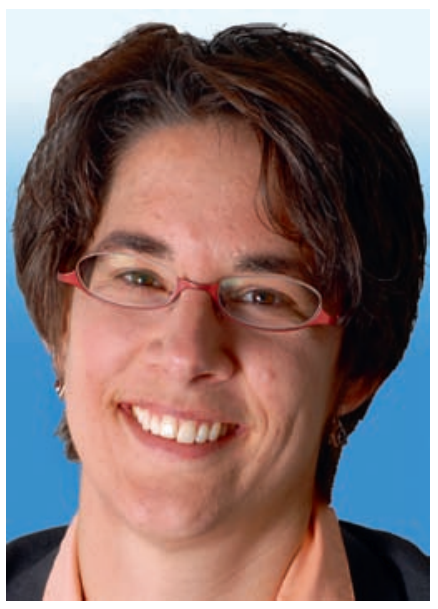

lic. phil.

Jacqueline Wettstein (FMH) 


\section{Redaktion Ethik}

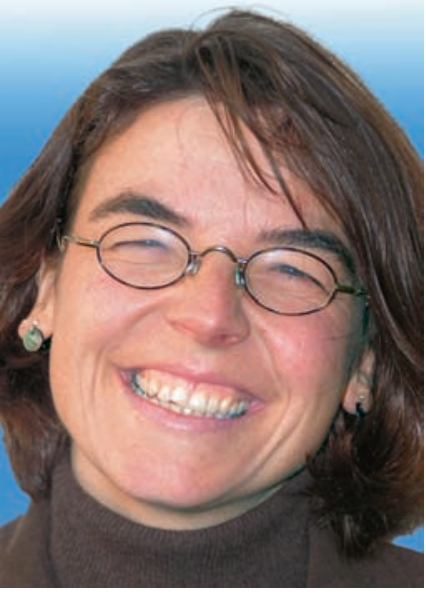

Dr. theol. Christina aus der $\mathrm{Au}$

\section{Redaktion Medizingeschichte}

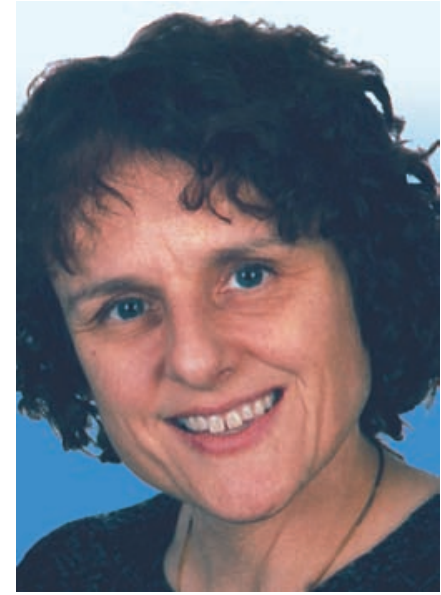

PD Dr. med. et lic. phil. Iris Ritzmann

\section{Redaktion Recht}

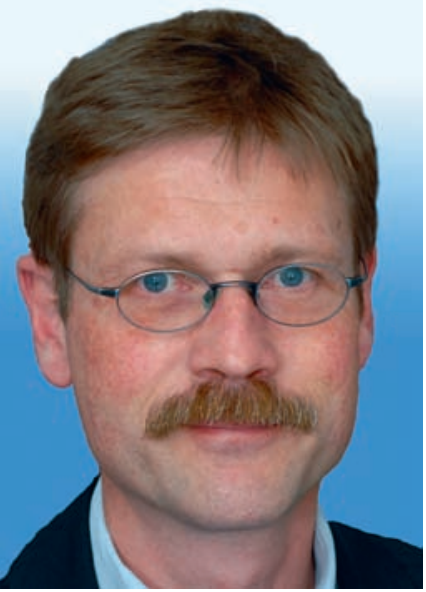

Fürsprecher

Hanspeter Kuhn (FMH)

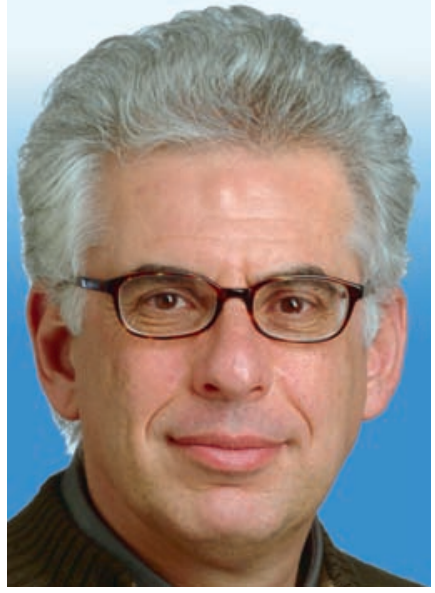

Prof. Dr. med. Lazare Benaroyo

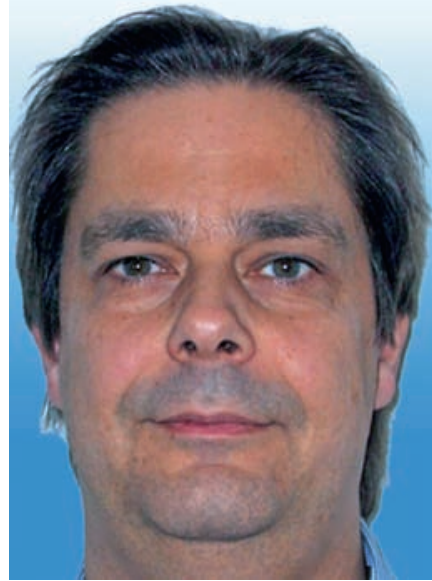

Dr. rer. soc. Eberhard Wolff

Managing Editor

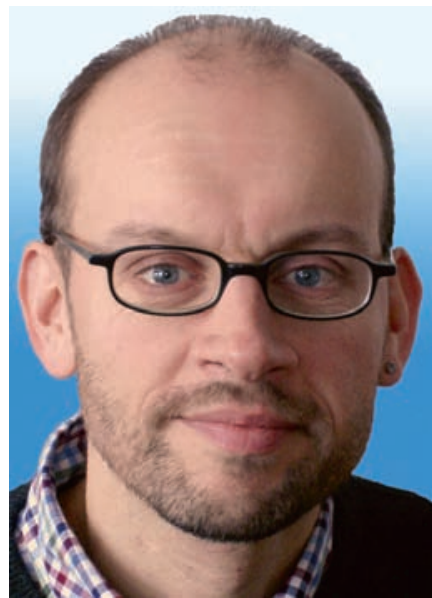

lic. phil. Thomas Heuer

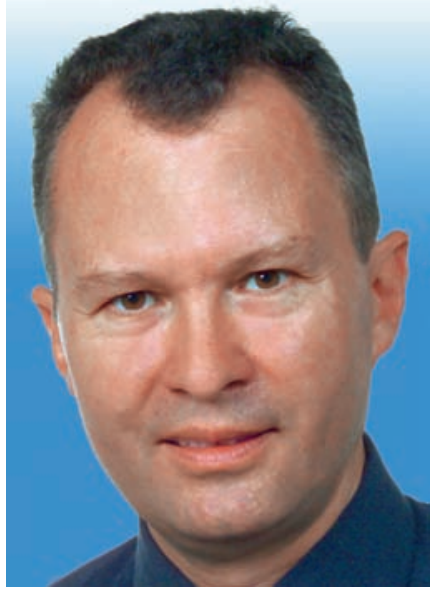

Prof. Dr. phil., dipl. biol.

Christoph Rehmann-Sutter

\section{Redaktion Ökonomie}

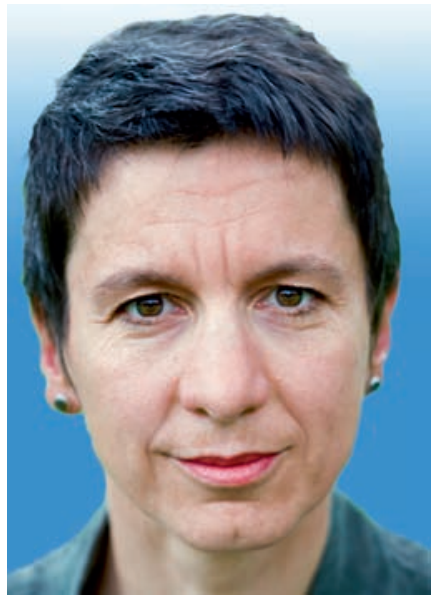

lic. oec. Anna Sax, MHA

Redaktionssekretariat

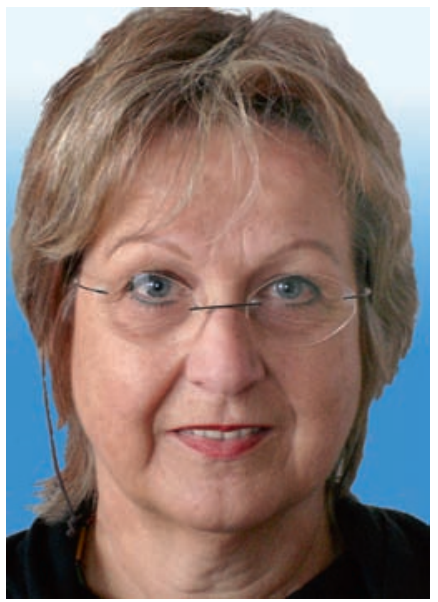

Margrit Neff 